\title{
Syndrome of transient Headache and Neurological Deficits with cerebrospinal fluid Lymphocytosis (HaNDL)
}

\author{
A Cifelli, ${ }^{1}$ L Vaithianathar ${ }^{2}$ \\ 1Department of Neurology, Queen's Hospital, Romford, Essex, UK; \\ 2Department of Neurology, Royal Derby Hospital, Derby, UK
}

Correspondence to A Cifelli, Alberto.Cifelli@nhs.net

\begin{abstract}
Summary
A lady in her late 20 s was admitted with a history of headaches and intermittent focal neurological symptoms which were greatly exacerbated by catheter angiography of the cerebral circulation. Cerebrospinal fluid analysis demonstrated a lymphocytic pleocytosis. She subsequently made a spontaneous recovery, without neurological sequelae. Her presentation fits the diagnostic criteria for the previously described syndrome of transient headache and neurological deficits with cerebrospinal fluid lymphocytosis (HaNDL). HaNDL is a probably underdiagnosed nosological entity, characterised by often dramatic clinical manifestations but ultimately a good prognosis.
\end{abstract}

\section{BACKGROUND}

HaNDL is probably not as rare as commonly thought. ${ }^{1}$ Awareness of its existence can avoid unnecessary and potentially harmful investigations and therapies.

\section{CASE PRESENTATION}

A lady in her late 20s was admitted to a district general hospital under the general medical team with a 3-week history of worsening unilateral headaches which were associated with photophobia, nausea and vomiting. In the few days preceding her admission to hospital, she had had one episode of right upper limb numbness and weakness, and slurred speech, lasting a few hours, bouts of unsteadiness and expressive dysphasia of a few minutes' duration and intermittent blurred vision. She had a past medical history of infrequent attacks of migraine without aura for few years, was on no medication, smoked only socially and drank alcohol in moderation. There was no history of illicit drug use or recent foreign travel.

On admission her vitals were normal, and she was alert and fully orientated. Her neurological examination and admission blood tests (including urea and electrolytes, liver function tests, glucose, full blood count, erythrocyte sedimentation rate, $\mathrm{C}$ reactive protein, coagulation screen) were within normal limits. Blood cultures were negative.

CT of the head was normal. A lumbar puncture (LP) was attempted several times before a cerebrospinal fluid (CSF) sample could be obtained. Protein levels were $2.97 \mathrm{~g} / \mathrm{l}$, glucose $3.2 \mathrm{mmol} / \mathrm{l}$ (contemporary plasma values were not available), white cell count (WCC) 145 (lymphocytes 97\%, atypical cells $2 \%$, polymorphonuclear cells $1 \%$ ), red blood cells (RBC) 11 440. Xanthochromia testing was positive. The opening pressure was not measured.

A subarachnoid haemorrhage was suspected, and she was transferred to the local university hospital under the care of the neurosurgeons, who found her to be neurologically intact on arrival. CT angiography was normal, and she went on to have a catheter angiogram. Ten minutes after the first dose of contrast was administered, she became dysarthric and 5 min later dysphasic and agitated. This was rapidly followed by fluctuating right hemiparesis, and speech and behavioural disturbance which settled over 20 min. Repeat angiography under general anaesthesia excluded vasospasm, arterial dissection and venous sinus thrombosis. She remained stable from the cardiovascular point of view during both angiograms.

On recovering from the anaesthetic, she was globally dysphasic, agitated and uncooperative. There was right hemifacial weakness of upper motor neuron type and mild right hemiparesis. The right knee jerk was exaggerated, and she had a right Babinski's response. MR with diffusion-weighted imaging (DWI) done $2 \mathrm{~h}$ post-angiography showed subtle cortical diffusion abnormalities in the left temporal region (figure 1). T2 and T1-weighted images were normal. A LP was repeated. The CSF was opalescent with an opening pressure of $8 \mathrm{~cm} \mathrm{H} \mathrm{H}_{2} \mathrm{O}$, protein $2.04 \mathrm{~g} / \mathrm{l}$, glucose $3.8 \mathrm{mmol} / \mathrm{l}$ (plasma 5.6), WCC 700 (all lymphocytes), RBC 300. Microscopy and culture (including viral and mycobacterial) were negative. CSF HSV, VZV and enterovirus PCR testing was negative as well.

After the angiograms, she was pyrexial for $24 \mathrm{~h}$ and was started on intravenous aciclovir. One day post-angiogram, her right hemiparesis and dysphasia began improving gradually. Two days after the angiograms, she had further imaging of the brain including magnetic resonance angiography (MRA), DWI and gradient-echo (GE) sequences. This showed mild cortical thickening and hyperintensity in the left frontal, temporal and insular regions on the T2-weighted (figure 2) and FLAIR images. MRA, DWI and GE were normal.

On day 7 from her transfer to the university hospital, she had an episode of left hemiparesis and neglect lasting a few hours. 


\section{BMJ Case Reports}

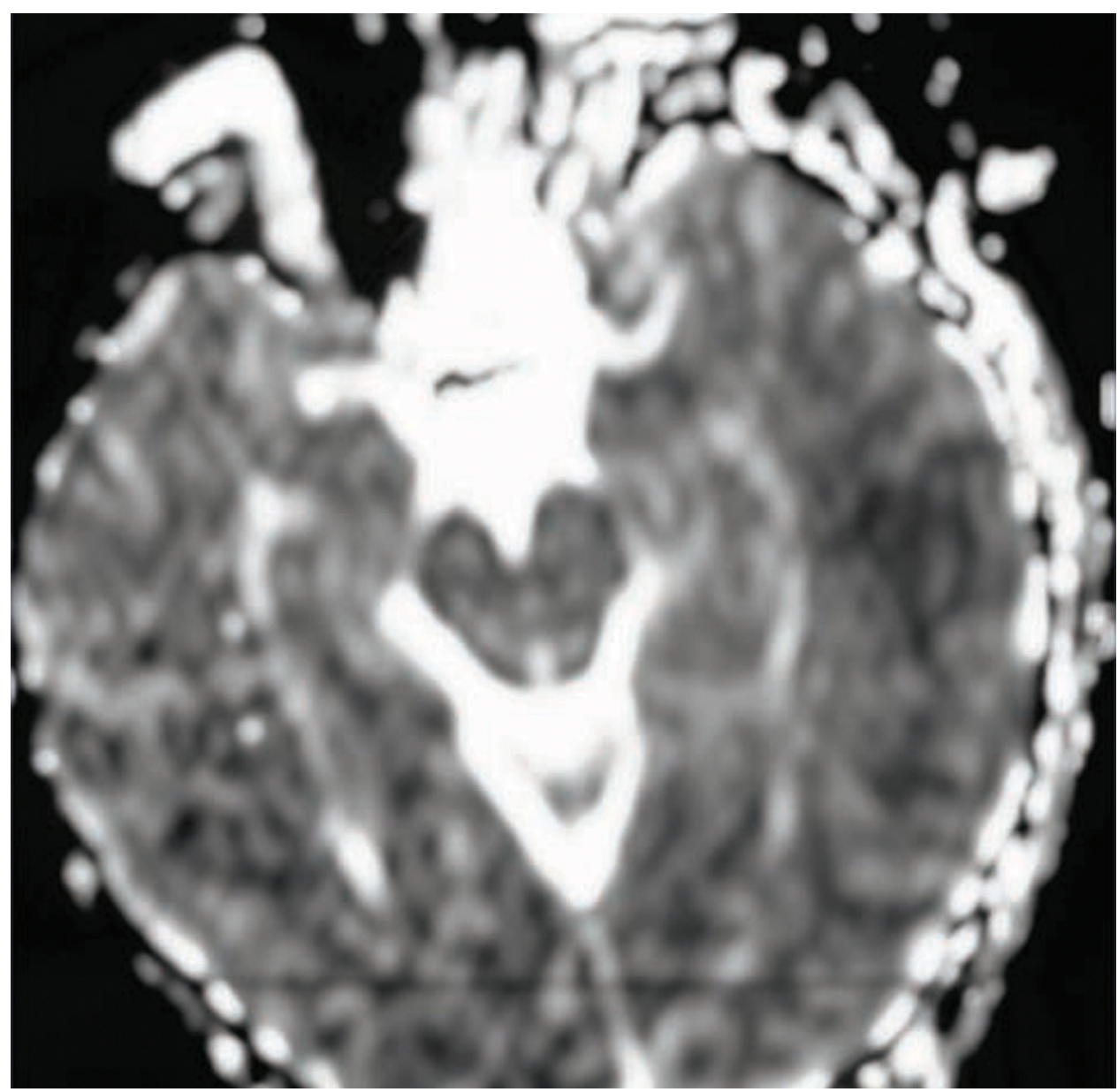

Figure 1 Subtle cortical diffusion abnormality in the left temporal region.

\section{DIFFERENTIAL DIAGNOSIS}

The differential diagnosis of HaNDL is broad and encompasses familial hemiplegic migraine, Lyme's disease, neurosyphilis, neurobrucellosis, granulomatous and neoplastic arachnoiditis, encephalitis, central nervous system vasculitis, meningitis (including HIV-related), mycoplasma infection of the CNS, Mollaret's meningitis and neurolupus.

\section{OUTCOME AND FOLLOW-UP}

She was discharged 2 days later on a 1-week course of oral aciclovir, by which stage all her focal neurological symptoms had settled although the headache persisted.

On arriving home, she had a bout of severe headache with vomiting which lasted $24 \mathrm{~h}$. Nine days after discharge, there was a further episode of exacerbation of the headache of $48 \mathrm{~h}$ duration, during which she had sensory disturbance in the left hemibody for a few hours.

She was reviewed in clinic 2 months after leaving hospital when she still had a mild constant headache but denied recurrence of focal neurological symptoms.

\section{DISCUSSION}

The Syndrome of transient Headache and Neurological Deficits with cerebrospinal fluid Lymphocytosis (HaNDL) (also known as pseudomigraine with lymphocytic pleocytosis or migraine - or migrainous syndrome - with CSF pleocytosis, or pseudomigraine with inflammatory CSF) was clearly described as a new entity by Swanson et a $\mathbb{R}^{2}$ in 1980 and contemporarily by Martí-Massó et al, ${ }^{3}$ although the very first case reported may have been published by Symonds in $1951^{4}$. Diagnostic criteria have been proposed in case series by Berg et al in $1995^{5}$ and by Gómez-Aranda et al in $1997^{6}$ and in the 2004 International Classification of Headache Disorders, second edition. ${ }^{7}$

HaNDL is a monophasic, self-limiting condition that runs its course usually within a few months from onset, without leaving any neurological sequelae. Exceptional instances of single attacks separated by up to 13 years have been reported..$^{8}$ It affects both adults and children ${ }^{9}$ although most cases belong to the third and fourth decades. HaNDL is characterised by episodes (from 1 to $>20$ ) of headache, which is usually severe, ${ }^{10}$ neurologic deficits involving different neurovascular territories, and CSF lymphocytic pleocytosis. The attacks last from a few hours to 3 days and are separated by symptom-free intervals. The onset of headache is often preceded by symptoms suggestive of a viral infection and/or fever in about a third of the cases. Interestingly, unlike migraine, it has a slight predilection for males. Moreover, most patients do not have a previous history of migrainous headaches. The neurological symptoms, which can develop before, during or after the headache, entails sensory symptoms (78\% of cases), aphasia 


\section{BMJ Case Reports}

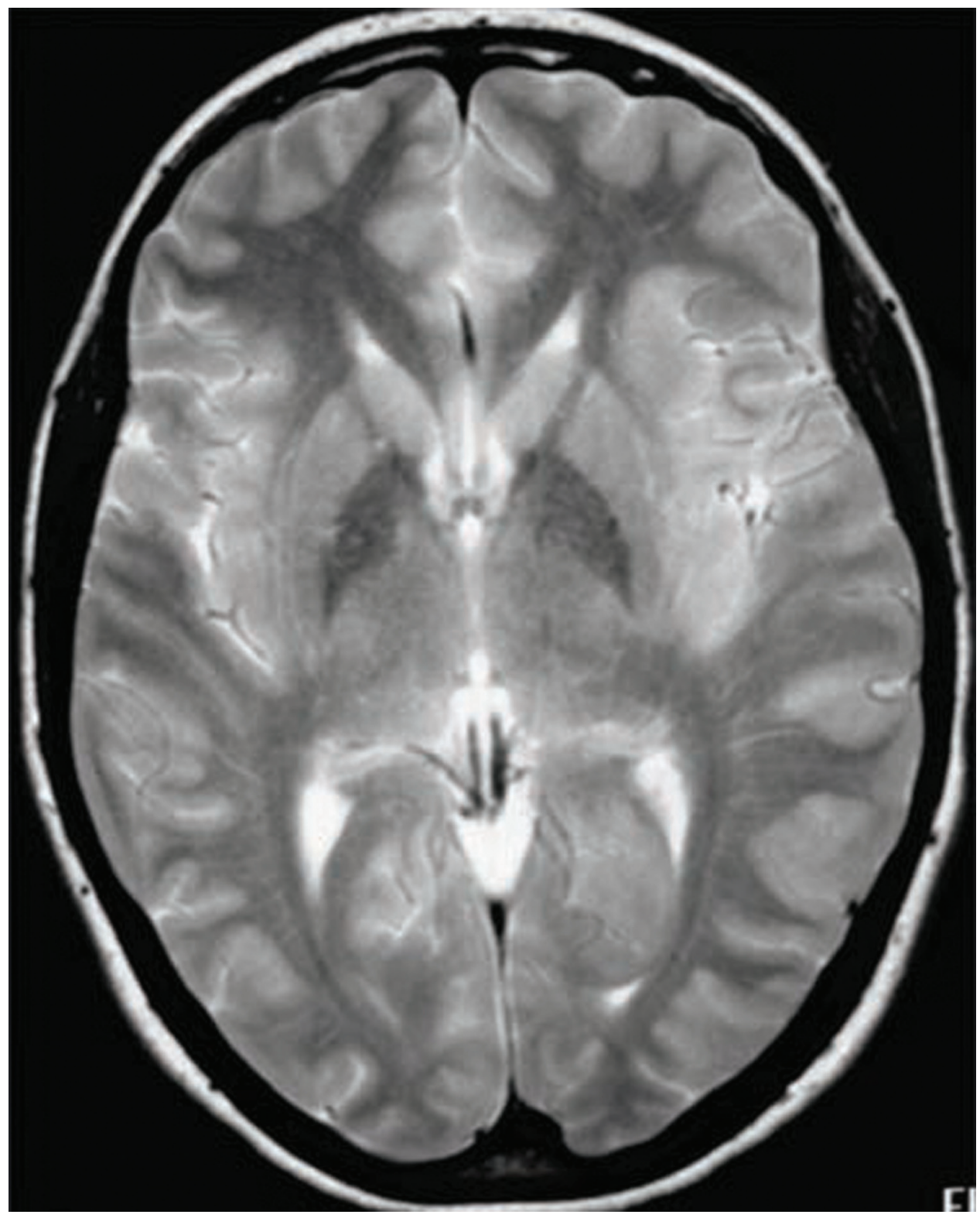

Figure 2 Mild cortical thickening and hyperintensity in the left frontal, temporal and insular regions on axial T2-weighted MRI.

$(66 \%)$ and motor deficits $(56 \%)$, while visual symptoms appear to be significantly rarer (18\%). Blood tests show occasional leucocytosis. On CSF sampling, there is raised opening pressure $\left(100-400 \mathrm{~mm} \mathrm{H}_{2} \mathrm{O}\right)$ in $>50 \%$ of cases, high protein levels $(20-250 \mathrm{mg} / \mathrm{dl})$ in $>90 \%$, lymphocytosis (10-760 cells/ml), normal glucose and no oligoclonal bands are observed. ${ }^{6}$ The CSF pleocytosis resolves with time, ${ }^{7}$ although its global duration has not been established. ${ }^{11}$ Both CSF and serum-based microbiological tests are normal (although there are exceptions to this). ${ }^{612-14}$

Conventional brain MRI is, as a rule, normal, and in fact Gómez-Aranda et al, ${ }^{6}$ posit this as a diagnostic criterion. However, there have reports of abnormal findings. ${ }^{6}$ 15-19 DWI has been reported to be normal in at least one case, both during and 'several hours' after an attack. ${ }^{20}$

Cerebral angiography has been almost invariably normal, ${ }^{6}$ and like in our case, has been responsible for triggering single episodes of neurological dysfunction. 56182122 Brain Single Photon Emission CT has revealed hypoperfusion of areas responsible for the clinical phenomenology both during the symptomatic and asymptomatic phase, ${ }^{6} 1723$ but also hyperperfusion ${ }^{17} 24$ of previously symptomatic regions, which the authors speculate to represent reactive hyperaemia. A recently published case, ${ }^{25}$ which was studied with CT-perfusion during the symptomatic phase, had global unihemispheric hypoperfusion, a finding already described by Fuentes et al. ${ }^{23}$ EEG shows transient focal slowing in the clinically affected hemisphere in $70-80 \%$ of the cases. ${ }^{6} 26$

The aetiopathogenesis of HaNDL has not been fully elucidated, but three major hypotheses have come to the fore. ${ }^{27} \mathrm{HaNDL}$ has been regarded by some authors as an atypical form of migraine. ${ }^{1} 2829$ However, several of its features militate against this view. First, unlike migraine, 
it is a monophasic illness and is more frequent in men. Second, the duration of the deficits is longer than in classical migraine and their characteristics are different from typical aura, where visual symptoms usually dominate the picture. Finally, although no systematic studies have addressed the composition of CSF in migraine, the general consensus (based on clinical experience, single case reports and a few case series) is that significant lymphocytic pleocytosis is distinctly unusual, even in hemiplegic forms. The model of HaNDL as a conventional meningoencephalitic illness is unconvincing, because of the universal absence of signs of meningeal irritation and the publication of only three reports implicating an infectious aetiology..$^{12} 1430$ It seems instead plausible that the primary pathogenetic mechanism in HaNDL is the activation of cortical spreading depression (probably by viral infection), which in turn incites sterile inflammation in the cortex and meninges through trigeminovascular activation. ${ }^{31}$

\section{Learning points}

- HaNDL is a regarded as a rare syndrome although it is probably underreported or misdiagnosed. ${ }^{27}$

- Although its clinical manifestations may be quite dramatic, the prognosis is good.

- In HaNDL, cerebral angiography can trigger an episode of neurological dysfunction, and this should be borne in mind when investigating headaches associated with focal neurological symptoms.

- The pathogenesis of HaNDL remains unclear.

\section{Competing interests None.}

Patient consent Not obtained.

\section{REFERENCES}

1. Lhermitte F, Marteau R, Roullet E. Migraine and CSF pleocytosis [letter]. Neurology 1982;32:1074.

2. Swanson JW, Bartleson JD, Whisnant JP. A migrainous syndrome with CSF pleocytosis [abstract]. Neurology 1980;30:418

3. Martí-Massó JF, Carrera N, Astudillo W, et al. Pseudomigraña con LCR inflamatorio. Reunión Extraordinaria dela Sociedad Española de Neurología. Jaca, España, 6-7, de junio de 1980.

4. Symonds C. Migrainous variants. Trans Med Soc Lond 1951;67:237-50.

5. Berg MJ, Williams LS. The transient syndrome of headache with neurologic deficits and CSF lymphocytosis. Neurology 1995;45:1648-54.

6. Gómez-Aranda F, Cañadillas F, Martí-Massó JF, et al. Pseudomigraine with temporary neurological symptoms and lymphocytic pleocytosis. A report of 50 cases. Brain 1997;120:1105-13.

7. Headache Classification Subcommittee of the International Headache Society. The international classification of headache disorders, 2nd Edn. Cephalalgia 2004;24:9-160.

8. Giorgetti A, Mariani G, Patruno GM, et al. The transient syndrome of headache with neurological deficits, cerebrospinal fluid pleocytosis and acute confusional state: a case report. J Headache Pain 2005:6:476.
9. Rossi LN, Vassella F, Bajc 0, et al. Benign migraine-like syndrome with CSF pleocytosis in children. Dev Med Child Neurol 1985:27:192-8.

10. Oldani A, Marcone A, Zamboni M, et al. The transient syndrome of headache with neurologic deficits and CSF lymphocytosis. Report of a case without severe headache. Headache 1998;38:135-7.

11. Toth CC. Persistent cerebrospinal fluid abnormalities in the syndrome of headache, neurological deficit, and cerebrospinal fluid lymphocytosis despite resolution of clinical symptomatology. Headache 2002;42:1038-43.

12. Ferrari MD, Buruma OJ, van Laar-Ramaker $\mathrm{M}$, et al. A migrainous syndrome with pleocytosis. Neurology 1983;33:813.

13. Vicente Mas J, Juni Sanahuja J, Benítez Bermejo R, et al. [Cytomegalovirus infection mimicking a pseudomigraine with pleocytosis]. An Med Interna 2004;21:360-1.

14. Castels-van Daele $\mathbf{M}$, Standaert L, Boel M, et al. Basilar migraine and viral meningitis. Lancet 1981:1:1366.

15. Shikishima K, Kitahara K, Inoue K. Ophthalmologic manifestations in headache, neurologic deficits, and cerebrospinal fluid lymphocytosis (HaNDL) syndrome with nonspecific frontal lesions and hyperthyroidism. Eye (Lond) 2006;20:613-15.

16. Arnold G, Reuter U, Kinze S, et al. Migraine with aura shows gadolinium enhancement which is reversed following prophylactic treatment. Cephalalgia 1998;18:644-6.

17. Caminero AB, Pareja JA, Arpa J, et al. Migrainous syndrome with CSF pleocytosis. SPECT findings. Headache 1997;37:511-15.

18. Lansberg MG, Woolfenden AR, Norbash AM, et al. Headache with neurological deficits and CSF lymphocytosis: A transient ischemic attack mimic. J Stroke Cerebrovasc Dis 1999;8:42-4.

19. Yilmaz A, Kaleagasi H, Dogu 0, et al. Abnormal MRI in a patient with 'headache with neurological deficits and CSF lymphocytosis (HaNDL)'. Cephalalgia 2010;30:615-19.

20. Gekeler F, Holtmannspötter M, Straube A, et al. Diffusion-weighted magnetic resonance imaging during the aura of pseudomigraine with temporary neurologic symptoms and lymphocytic pleocytosis. Headache 2002;42:294-6.

21. Bartleson JD, Swanson JW, Whisnant JP. A migrainous syndrome with cerebrospinal fluid pleocytosis. Neurology 1981;31:1257-62.

22. Durieux A, Carriere N, Clavelou P. [Pseudomigraine with transient neurological signs and lymphocytic pleiocytosis]. Rev Neurol (Paris) 2000; 156:285-7.

23. Fuentes B, Diez Tejedor E, Pascual J, et al. Cerebral blood flow changes in pseudomigraine with pleocytosis analyzed by single photon emission computed tomography. A spreading depression mechanism? Cephalalgia 1998;18:570-3.

24. Tsukamoto T, Miyazawa K, Narikawa K, et al. [A young woman with pseudomigraine with CSF pleocytosis]. Rinsho Shinkeigaku 2003; 43:12-15.

25. Pettersen JA, Aviv RI, Black SE, et al. Global hemispheric CT hypoperfusion may differentiate headache with associated neurological deficits and lymphocytosis from acute stroke. Stroke 2008;39:492-3.

26. Martin-Balbuena S, Arpa-Gutierrez FJ. [Pseudomigraine with cerebrospinal fluid pleocytosis or syndrome of headache, temporary neurological deficit and cerebrospinal fluid. A historical review]. Rev Neurol 2007:45:624-30

27. Pascual J, Valle N. Pseudomigraine with lymphocytic pleocytosis. Curr Pain Headache Rep 2003;7:224-8.

28. Schraeder PL, Burns RA. Hemiplegic migraine associated with an aseptic meningeal reaction. Arch Neurol 1980;37:377-9.

29. Day TJ, Knezevic W. Cerebrospinal-fluid abnormalities associated with migraine. Med J Aust 1984:141:459-61.

30. Richert JR, Potolicchio S Jr, Garagusi VF, et al. Cytomegalovirus encephalitis associated with episodic neurologic deficits and OKT-8+ pleocytosis. Neurology 1987:37:149-52.

31. Bolay H, Reuter U, Dunn AK, et al. Intrinsic brain activity triggers trigeminal meningeal afferents in a migraine model. Nat Med 2002;8:136-42. 


\section{BMJ Case Reports}

This pdf has been created automatically from the final edited text and images.

Copyright 2011 BMJ Publishing Group. All rights reserved. For permission to reuse any of this content visit http://group.bmj.com/group/rights-licensing/permissions.

BMJ Case Report Fellows may re-use this article for personal use and teaching without any further permission.

Please cite this article as follows (you will need to access the article online to obtain the date of publication).

Cifelli A, Vaithianathar L. Syndrome of transient Headache and Neurological Deficits with cerebrospinal fluid Lymphocytosis (HaNDL). BMJ Case Reports 2011;

10.1136/bcr.03.2010.2862, date of publication

Become a Fellow of BMJ Case Reports today and you can:

- Submit as many cases as you like

- Enjoy fast sympathetic peer review and rapid publication of accepted articles

- Access all the published articles

Re-use any of the published material for personal use and teaching without further permission

For information on Institutional Fellowships contact consortiasales@bmjgroup.com

Visit casereports.bmj.com for more articles like this and to become a Fellow 